\title{
Personal monitoring to reduce exposure to black carbon in children with asthma: a pilot study
}

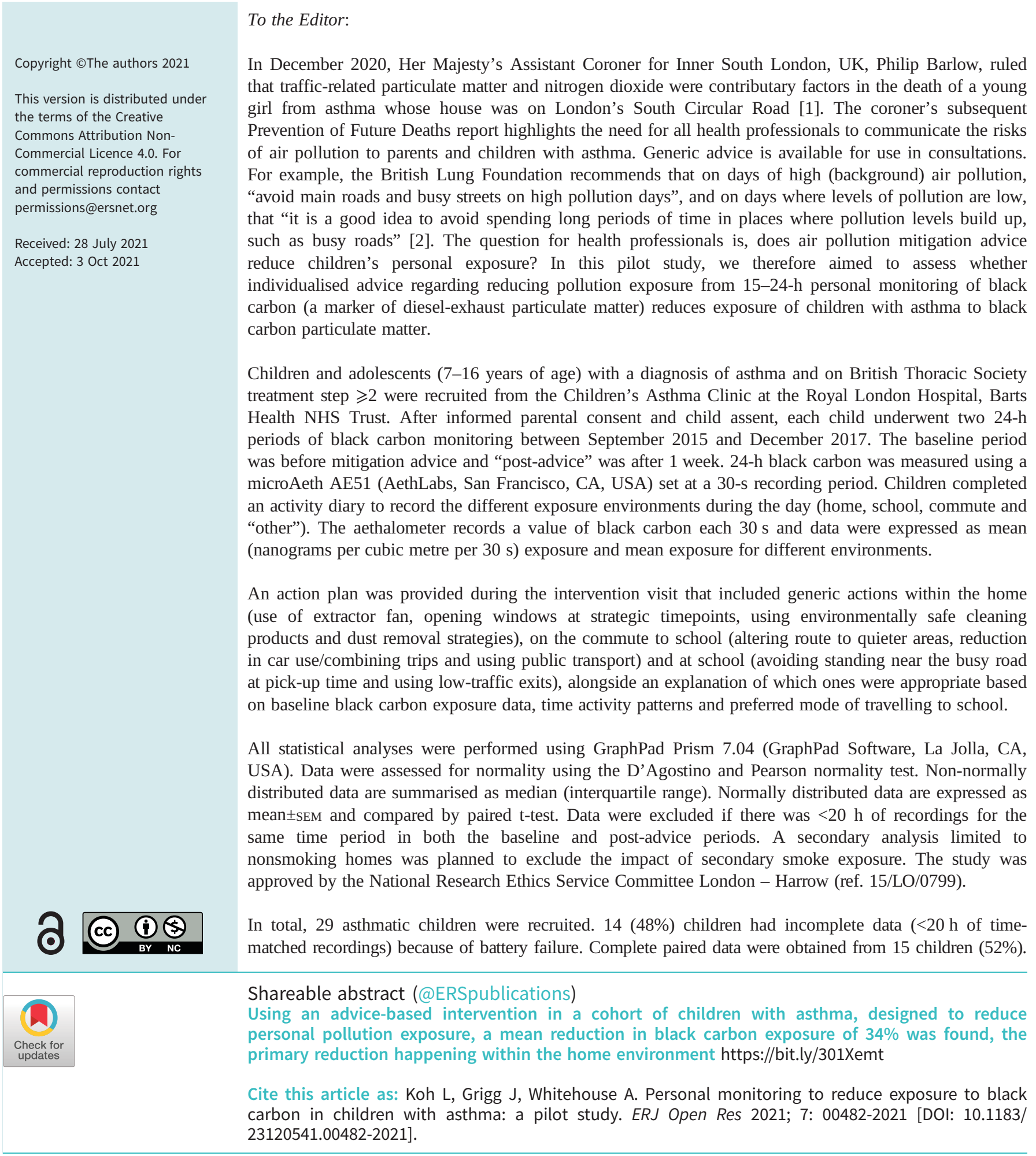


The majority of children were from nonsmoking households (69\%), $60 \%$ of families used a gas stove for cooking and $40 \%$ primarily walked to school.

At baseline, the median proportion of black carbon exposure at home was 41.0 (29-54)\%, for commute to school was 9.7 (1.8-22.1)\%, 34.5 (23.5-45.5)\% for school and $4.4(0-17) \%$ for other. Black carbon concentrations at baseline were: overall, $1752(1232-2231) \mathrm{ng} \cdot \mathrm{m}^{-3}$; home, $1164(658-2231) \mathrm{ng} \cdot \mathrm{m}^{-3}$; commute, 4204 (2522-7534) ng $\cdot \mathrm{m}^{-3}$; and school, $1863(876-3887) \mathrm{ng} \cdot \mathrm{m}^{-3}$.

Since differences between baseline and post-advice black carbon were normally distributed, paired t-test analysis was used. Compared with baseline, post-advice black carbon was reduced (change $-1038 \pm 265 \mathrm{ng} \cdot \mathrm{m}^{-3}, \mathrm{n}=15 ; \mathrm{p}<0.01$ ) (figure 1a) with a mean reduction in black carbon exposure of $34.4 \pm 10.05 \%$. There was no difference in the time spent in the different microenvironments between baseline and post-advice. For the different microenvironments, there was a significant reduction in black carbon at home (change $-603.5 \pm 212 \mathrm{ng} \cdot \mathrm{m}^{-3}, \mathrm{p}=0.013$ ) (figure 1b). By contrast, there was no reduction in mean black carbon for either the commute (change $-2857 \pm 1599 \mathrm{ng} \cdot \mathrm{m}^{-3}, \mathrm{p}=0.095$ ) (figure $1 \mathrm{c}$ ) or at school (change $-1279 \pm 680 \mathrm{ng} \cdot \mathrm{m}^{-3}, \mathrm{p}=0.081$ ) (figure 1d).

An analysis limited to nonsmoking homes also demonstrated a significant reduction. In this subgroup, compared with baseline, post-advice black carbon was reduced (change $-1349 \pm 312 \mathrm{ng} \cdot \mathrm{m}^{-3}$ per $30 \mathrm{~s}, \mathrm{n}=11$; $\mathrm{p}<0.01$ ) and there was a significant reduction in black carbon at home (change $-778.8 \pm 268.4 \mathrm{ng} \cdot \mathrm{m}^{-3}$ per $30 \mathrm{~s}, \mathrm{p}=0.013)$.

We found that the MicroAeth generated high-quality individual exposure data, with expected black carbon peaks during children's commute to school. However, the limited battery life of the device resulted in significant loss of paired data. Despite this, paired data were available for 15 children. In this subgroup, the proportion of black carbon exposure in the different exposure environments was broadly compatible with our small study of six healthy children that informed a UNICEF report [3]. This is not the first time that microenvironment exposures have been reported in children with asthma, such as those reported by Rabinovitch et al. [4] in 2016, and Hwang and Lee [5] in 2018. However, it is the first time personal black carbon exposure profiles have been used to guide advice on exposure-mitigation options in children with asthma across multiple microenvironments.
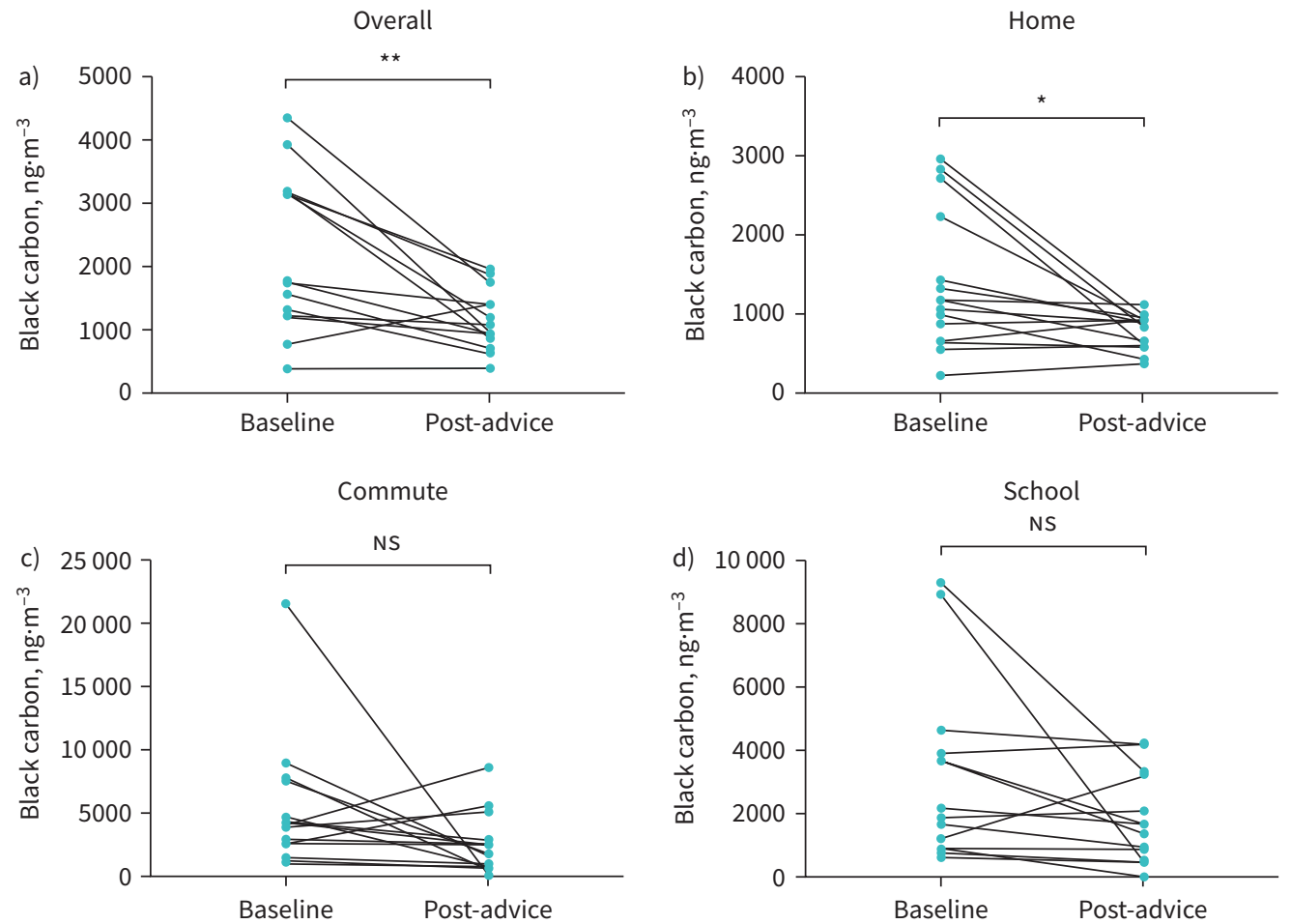

FIGURE 1 Change in black carbon between baseline and post-advice for a) mean overall $24 \mathrm{~h}$, b) home, c) commute and d) school. Ns: not significant. ${ }^{*}$ : $p<0.05 ;{ }^{\star \star}: p<0.01$. 
The reduction in mean 24-h black carbon after advice provides preliminary evidence of the effectiveness of black carbon exposure mitigation advice to children and parents. However, analysis of black carbon change by microenvironment suggests that the overall reduction in black carbon was due to reduced indoor exposure and not reduced exposure during the commute. Although we did not record specific indoor changes, parents reported that they tried to keep children away from the kitchen during cooking. Indeed, previous studies have investigated the use of home monitoring to reduce smoking within the home [6], but in the present study, changes in smoking behaviour is unlikely to be a major factor, since a significant reduction in mean 24-h black carbon exposure and black carbon home exposure was present in the analysis limited to the 11 nonsmoking households. The absence of change in black carbon post-advice on commute exposure may either be due to lack of study power or that children had little option in the way they travelled to school. To determine effects on commute will need larger studies.

The study had its limitations. Firstly, we used black carbon monitors rather than particulate matter (for which health guidelines are written). This was due to effectiveness and usability of monitors, with the MicroAeth known as a well validated monitor for personal monitoring [7, 8]. Black carbon is known to correlate strongly with traffic-related air pollutant and household particulate matter [9]. Secondly, while we asked for feedback on the interventions, this was not related back to individual datasets. This would be important in future studies intending to do this on a wider scale. Finally, the datasets usable for analysis were strongly impacted by the battery life of the monitors. We have now developed good, structured advice that ensures that the monitors last the full monitoring period, which can be implemented in future studies.

In summary, using personal black carbon monitoring and feedback, this pilot study suggests that it is possible to reduce black carbon exposure of asthmatic children. Our data suggest that exposure indoors may be more amenable to this intervention than outdoor exposure.

Lee Koh, Jonathan Grigg (1) and Abigail Whitehouse 주

Centre for Genomics and Child Health, Queen Mary University of London, London, UK.

Corresponding author: Abigail Whitehouse (a.whitehouse@qmul.ac.uk)

Provenance: Submitted article, peer reviewed.

Conflict of interest: J. Grigg reports personal fees from GSK, Vifor Pharma, AstraZeneca, Novartis and Omron outside the submitted work. A. Whitehouse and L. Koh have no disclosures.

Support statement: This study was supported by an Asthma UK PhD studentship. Funding information for this article has been deposited with the Crossref Funder Registry.

\section{References}

1 London Inner South Coroner's Court. Inquest touching the death of Ella Roberta Adoo Kissi-Debrah. https:// www.innersouthlondoncoroner.org.uk/news/2020/nov/inquest-touching-the-death-of-ella-roberta-adoo-kissidebrah. Date last updated: 18 November 2020. Date last accessed: 16 December 2020.

2 British Lung Foundation. How can I protect myself from air pollution? https://www.blf.org.uk/support-for-you/ air-pollution/tips. Date last updated April 2020. Date last accessed: 16 December 2015.

3 UNICEF UK. The toxic school run. London, UNICEF UK, 2019.

4 Rabinovitch N, Adams CD, Strand M, et al. Within-microenvironment exposure to particulate matter and health effects in children with asthma: a pilot study utilizing real-time personal monitoring with GPS interface. Environ Health 2016; 15: 96.

5 Hwang Y, Lee K. Contribution of microenvironments to personal exposures to PM. AtmEn 2018; 175: 192-198.

6 Vardavas C, Semple SRD, O'Donnell R, et al. Measuring for change: a multi-centre pre-post trial of an air quality feedback intervention to promote smoke-free homes. Environ Int 2020; 140; 105738.

7 Aethlabs. microAeth ${ }^{\oplus / A E 51 . ~ h t t p s: / / a e t h l a b s . c o m / m i c r o a e t h / a e 51 / o v e r v i e w . ~ D a t e ~ l a s t ~ u p d a t e d: ~ 2021 . ~ D a t e ~ l a s t ~}$ accessed: 9 February 2021.

8 Cai J, Yan B, Ross J, et al. Validation of MicroAeth ${ }^{\circledR}$ as a black carbon monitor for fixed-site measurement and optimization for personal exposure characterization. Aerosol Air Qual Res 2014; 14: 1-9.

9 Whitehouse A, Barratt B, Grigg J. Does modelled exposure of children to particulate matter air pollution for the school address reflect personal exposure to black carbon? Eur Respir J 2016; 48: Suppl. 60, PA1320. 